\title{
HEALTH RISK ASSESSMENT OF BLACK CARBON EMISSION FROM FOSSIL FUEL
}

\author{
Md. Dulal Hossain Khan ${ }^{1,2 *}$, Mahima Sultana Sarkar ${ }^{1}$, Syeda Sadika Haque ${ }^{2}$ \\ and Md. Amjad Hossain ${ }^{3}$ \\ ${ }^{1}$ Department of Chemistry, Comilla University, Cumilla-3506, Bangladesh \\ ${ }^{2}$ Department of Chemistry, University of Dhaka, Faculty of Science, Dhaka 1000, Bangladesh \\ ${ }^{3}$ Institute of Leather Engineering and Technology, University of Dhaka
}

Received: 15 March 2021

Accepted: 04 May 2021

\begin{abstract}
Fossil fuel combustion is one of the major sources of carbonaceous emission throughout the world. In this study, two light absorbing carbonaceous aerosol namely Black carbon (BC) and Brown carbon (BrC) from fossil fuel combustion under controlled laboratory condition was reported. Four different fossil fuels; octane, petrol, diesel and kerosene was taken as samples (Four different fossil fuels; octane, petrol, diesel, and kerosene samples were collected from filling station of Nilkhet, Dhaka City. Two wavelengths Aethalometer (OT21) had been taken for systematic analysis of Black carbon and Brown carbon. BC and BrC particulates were determined in terms of density, concentration, emission and emission factor. The concentrations of Black carbon in $\mathrm{mgm}^{-3}$ for respective fuel samples were kerosene (3.83), diesel (4.59), petrol (7.94), octane (13.18) while concentrations of Brown carbon were kerosene (7.77), diesel (7.98), petrol (13.61), octane (20.46). BrC concentrations were found to be higher than those of $B C$ for all the fuel samples. Average concentrations of Black carbon and Brown carbon were $7.38 \mathrm{mgm}^{-3}$ and $11.46 \mathrm{mgm}^{-3}$ respectively. Thereafter, health risk assessment for chronic exposure to Black carbon was done (estimated/ evaluated/calculated) according to the U.S. EPA human health risk assessment protocol. Experimental results were correlated with the data given by the Exposure Factors Handbook of EPA for assessing carcinogenic and non-carcinogenic risk associated with $B C$. Total carcinogenic risk (CR) was found to be 3.27 for adults and 1.34 for children. While total noncarcinogenic risk i.e hazard quotient (HQ) for adults and children were 243.32 and 594.32 respectively. Both $C R$ and $H Q$ values crossed the safe limit given by the US EPA protocol indicating high probability of the occurrence of adverse health effects.
\end{abstract}

Keywords: Black carbon, Brown carbon, Fine particulates, Exposure, Aethalometer, Health risk.

\section{INTRODUCTION}

Black carbon is a distinct type of carbonaceous material that is formed primarily in flames during combustion of carbon-based fuels. It strongly absorbs visible light with a mass absorption cross section of at least $5 \mathrm{~m}^{2} \mathrm{~g}^{-1}$ at a wavelength of $550 \mathrm{~nm}$ (Olson et al. 2015). BC particles fall under inhalable fine particulates and thus can be deeply inhaled and deposited in the lungs or other airways. Causing many serious respiratory problems such as oxidative stress damage, respiratory irritation symptom (Olson et al. 2015 and Salam et al. 2013). Strong solar radiation region such as tropical area are particularly especially at risk from black carbon emission (Salam et al. 2013). Primary source of BC is the incomplete combustion of biomass and fossil fuel in the absence of oxygen. Black carbon stays in the atmosphere for just days to weeks (usually 7 to 10 days), but it can do a lot of lasting damage. The contribution to warming by one gram of $\mathrm{BC}$ is 100 to 2,000 times more than one gram of $\mathrm{CO}_{2}$ on a 100-year time scale (Vanloon et al. 2011). In the year 2011 scientists from NASAs Goddard Institute for Space Studies found that as much as a quarter of Arctic warming is caused by BC (Bond et al. 2004).

Brown carbon on the other hand is a fraction of organic carbon (OC) that can share primary sources with $\mathrm{BC}$ but also can originate from soil humic matter or biogenic sources (e.g. plant debris and fungi). Like BC, the primary sources of brown carbon are biomass burning, fossil fuel combustion, forest fire, soil eruption etc. Although less, they also contribute to light absorption in atmospheric aerosols. This particulate matter appears light brown to yellowish (Bond et al. 2001 and Patterson et al. 1984). Particles from smoldering combustion or from residential coal combustion (Bond et al. 2001) can contain substantial amounts of BrC.

Most aerosols in the smoke of combustion are an internal mixture of black and brown carbon. BrC is present independently it has nearly $15 \%$ potential to warm the atmosphere by absorbing light. However, health risk

*Corresponding Author: ch031dulal@gmail.com

https://www2.kuet.ac.bd/JES/

ISSN 2075-4914 (print); ISSN 2706-6835 (online) 
associated with $\mathrm{BrC}$ has not yet been found (Adler et al. 2011). A number of motor vehicles are restlessly running in Dhaka city. Most of which are run through incomplete combustion of fossil fuels releasing dense black smoke into the atmosphere (BRTA, 2019). Two major carbonaceous aerosols namely Black carbon (BC) and Brown carbon $(\mathrm{BrC})$ are notably present in this smoke which are receiving utmost concern due to disastrous environment and health issues recent years. Therefore the aim of this study is to systematic determination of $\mathrm{BC}$ and $\mathrm{BrC}$ in combustion smoke as well as studying their health risk associated with inhalation of $\mathrm{BC}$ in terms of carcinogenic risk (CR) and Hazard Quotient (HQ).

\section{METHODOLOGY}

\subsection{Sample Collection and Study Site}

In this study, four different fossil fuels; Octane, Petrol, Diesel and Kerosene were collected from Pother Bondhu Filling Station, Nilkhet, Dhaka (Figure 1). Sampling was done in the Inorganic and Analytical Chemistry laboratory, Department of Chemistry, University of Dhaka and combustion of fossils were done under controlled laboratory conditions. One stage open face 9633, "NILU" filter holder was used for sampling of different fossil fuels.

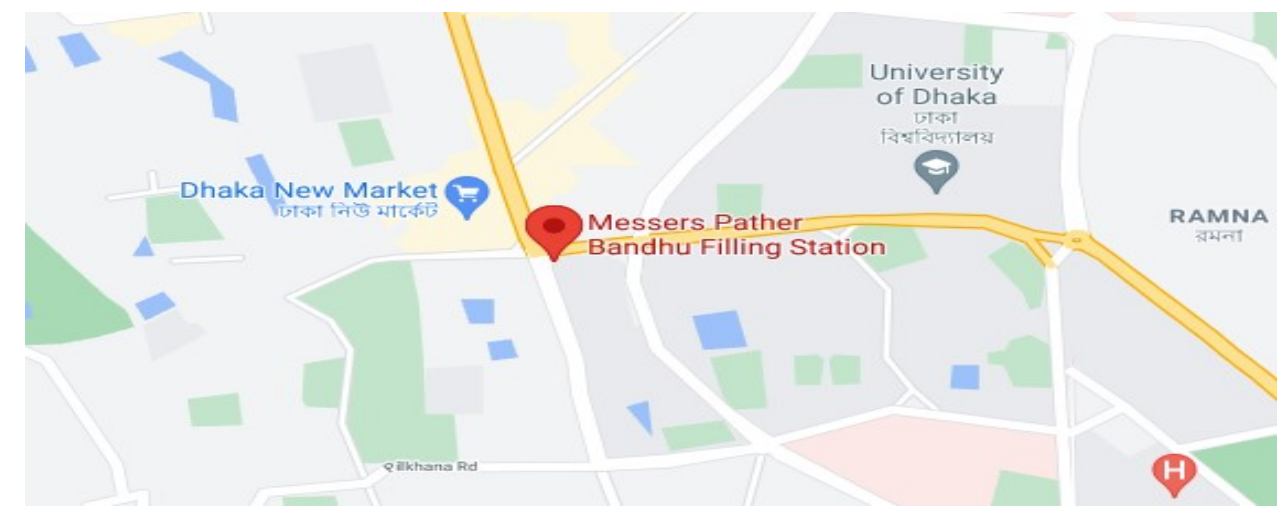

Figure 1: Images of sampling location Messers pather Bandhu filling Station, Nilkhet, Dhaka (Source: Google Map)

\subsection{Experimental Procedure}

Particulate matter was collected in quartz filters. (German, membrane filters, tissue quartz 2500 qat-up, $47 \mathrm{~mm}$ diameter). Every filter paper was heated at $800{ }^{\circ} \mathrm{C}$ for 4 hours before sampling to eliminate all organic impurities. About $50.0 \mathrm{~mL}$ of each fossil fuel was taken for combustion. The measurement of deposited PM weight from difference between loaded and unloaded filters was carried out. From the difference between initial and final gas meter reading the amount of air is measured. The PM loaded filters which were collected for 5 seconds were used for characterization of $\mathrm{BC}$ and $\mathrm{BrC}$.

\subsection{Characterization Technique}

The soot scan ${ }^{\mathrm{TM}}$ Model OT21 Transmissometer bench top analyser was used for measuring black carbon and brown carbon particulate matter (PM) from a variety of sample filters. Aethalometer contains a 2 wavelength light source; $880 \mathrm{~nm}$ providing the quantitative measurement of black carbon and $370 \mathrm{~nm}$ for quantitative measurement of brown carbon (Adler et al. 2011 and Cheng et al. 2015). The density, concentration, emission and emission factor of black and brown carbon were determined by using Aethalometer reading at 880 and 370 $\mathrm{nm}$, respectively. All equations related to the determination of $\mathrm{BC}$ and $\mathrm{BrC}$ parameters are suggested from ARCADIS, USA (Lin et al. 2019 and USEPA, 2019).

\section{$2.4 \quad$ Health Risk Evaluation of BC}

Health risk evaluation was done on the basis of the U.S. EPA human health risk assessment model. Theoretical carcinogenic and non-carcinogenic risk was calculated using the, CDI (Chronic Daily Intake in mg/Kg/day) (US EPA 2009).

$\mathrm{CDI}=\mathrm{C} \times \mathrm{I} \mathrm{R} \times \mathrm{EF} \times \mathrm{ED} /(\mathrm{BW} \times \mathrm{AT})$

$\mathrm{C}$ is the concentration of $\mathrm{BC}$ in $\mathrm{mgm}^{-3}$ and other parameters with their reference values are shown in Table 1. 
Table 1: Required parameters for health risk assessment study (Deng et al. 2016 and EPA, 2000 )

\begin{tabular}{llc}
\hline Parameters & \multicolumn{1}{c}{ Recommended value } \\
\cline { 2 - 3 } IR (Inhalation rate) & Children & Adult \\
\cline { 2 - 3 } EF (Exposure frequency) & $7.6 \mathrm{~m}^{3}$ day $^{-1}$ & $20 \mathrm{~m}^{3}$ day $^{-1}$ \\
ED (Exposure duration) & 346 days year & \\
BW (Body weight) & 6 years & 26 years \\
AT (Averaging time) & $15 \mathrm{~kg}$ & $70 \mathrm{~kg}$ \\
\hline
\end{tabular}

\subsection{Characterization of Carcinogenic Risk}

To determine the carcinogenic risk, the lifetime carcinogenic risk (CR) was measured which is defined as the possibility of identifying cancer over a lifetime exposure (Navid et al. 2019).

$\mathrm{CR}=\mathrm{CDI} \times \mathrm{CSF}$

where, CSF is cancer slope factor $=1.1\left(\mathrm{mgKg}^{-1} \mathrm{day}^{-1}\right)^{-1}(\mathrm{EPA} 2000)$.

\subsection{Characterization of Non-carcinogenic Risk}

Non-cancer risk was assessed by evaluating the Hazard Quotient (HQ). Where the inhalation toxicity reference doses for BC in our study is $5 \times 10^{-3} \mathrm{mg} \mathrm{m}^{-3}$.

$\mathrm{HQ}=\mathrm{CDI} / \mathrm{RfC}$ (Feng et al. 2019)

HQ value larger than 1 signifies that the exposed population is anticipated to have adverse non-cancer effects (EPA, 2009).

\section{RESULTS AND DISCUSSIONS}

\subsection{Density and Concentration Factors}

Table 2 summarizes the experimental results of $\mathrm{BC}$ and $\mathrm{BrC}$ parameters obtained from Aethalometer reading. For all fossil fuels concentration of all $\mathrm{BrC}$ was much greater than those of $\mathrm{BC}$. Both $\mathrm{BC}$ and $\mathrm{BrC}$ concentrations levels were highest in octane and lowest in kerosene. The average concentration of $\mathrm{BC}$ was 7.38 $\mathrm{mgm}^{-3}$, while that of $\mathrm{BrC}$ was $11.46 \mathrm{mgm}^{-3}$. Average emission of $\mathrm{BC}$ was $0.10 \mathrm{mgj}^{-1}$ and that of $\mathrm{BrC}$ was 0.16 $\mathrm{mgj}^{-1}$. The $\mathrm{BrC}$ emission was 1.57 times higher for diesel, 1.17 times higher for octane, 1.58 times higher for petrol and 2.8 times higher for kerosene.

Table 2: Density (in $\mu \mathrm{gcm}^{-3}$, concentration (in $\mathrm{mg} / \mathrm{m}^{3}$ ), emission (in $\mathrm{mgj}^{-1}$ ) and emission factor (in $\mathrm{mg} \cdot \mathrm{g}^{-1}$ ) of $\mathrm{BC}$ and $\mathrm{BrC}$ for all fossil fuels used in this study.

\begin{tabular}{lllllllll}
\hline \multirow{2}{*}{ Fossil fuel } & \multicolumn{3}{c}{ Density } & \multicolumn{2}{c}{ concentration } & \multicolumn{2}{c}{ Emission } & \multicolumn{2}{c}{ emission factor } \\
\cline { 2 - 9 } & $\mathrm{BC}$ & $\mathrm{BrC}$ & $\mathrm{BC}$ & $\mathrm{BrC}$ & $\mathrm{BC}$ & $\mathrm{BrC}$ & $\mathrm{BC}$ & $\mathrm{BrC}$ \\
\hline Diesel & 4.09 & 7.10 & 4.59 & 7.98 & 0.07 & 0.11 & 0.80 & 1.27 \\
Octane & 9.39 & 14.58 & 13.18 & 20.46 & 0.17 & 0.20 & 1.93 & 3.01 \\
Petrol & 5.66 & 9.69 & 7.94 & 13.61 & 0.12 & 0.19 & 1.28 & 2.18 \\
Kerosene & 2.05 & 4.45 & 3.83 & 7.77 & 0.05 & 0.14 & 0.62 & 1.25 \\
\hline
\end{tabular}

\subsection{Health Risk Evaluation}

Table 3 summarizes the cancer risk (CR) as well as non-cancer risk (HQ) caused by BC for children and adults. As recommended by US EPA, The acceptable risk levels for carcinogens should be larger than $10^{-6}$ (EPA, 2000). Carcinogenic risks (CR) of adults and children due to $B C$ exposure was higher than the permissible limit indicating that Black carbon exposure may bring about considerable carcinogenic health hazard in this region. Adults (3.27) were found to have approximately 2.4 times higher CR level as compared to children (1.34). The total non-carcinogenic risk in terms of Hazard Quotient (HQ) caused to different populations was adult (243.32) and children (594.32) indicating that exposure to BC is strongly responsible for producing adverse non-cancer 
effects. Children have 2.4 times higher HQ values as compared to adults. Which predicts that children are more prone to suffer non-cancer effects.

Table 3: Carcinogenic risk and non-carcinogenic risk assessment for black carbon

\begin{tabular}{lllllll}
\hline & \multicolumn{2}{c}{ CDI $(\mathrm{mg} / \mathrm{kg} /$ day $)$} & \multicolumn{2}{c}{ CR } & HQ \\
\cline { 2 - 6 } Fossil fuel & Adults & Children & Adults & Children & Adults & Children \\
\hline Diesel & $4.62 \times 10^{-1}$ & $1.89 \times 10^{-1}$ & $5.08 \times 10^{-1}$ & $2.08 \times 10^{-1}$ & 37.79 & 92.35 \\
Octane & $13.3 \times 10^{-1}$ & $5.43 \times 10^{-1}$ & $14.6 \times 10^{-1}$ & $5.97 \times 10^{-1}$ & 108.52 & 265.17 \\
Petrol & $7.99 \times 10^{-1}$ & $3.27 \times 10^{-1}$ & $8.79 \times 10^{-1}$ & $3.60 \times 10^{-1}$ & 65.37 & 159.75 \\
Kerosene & $4.85 \times 10^{-1}$ & $1.58 \times 10^{-1}$ & $4.24 \times 10^{-1}$ & $1.73 \times 10^{-1}$ & 31.53 & 77.05 \\
Total & 3.08 & 1.22 & 3.27 & 1.34 & 243.32 & 594.32 \\
\hline
\end{tabular}

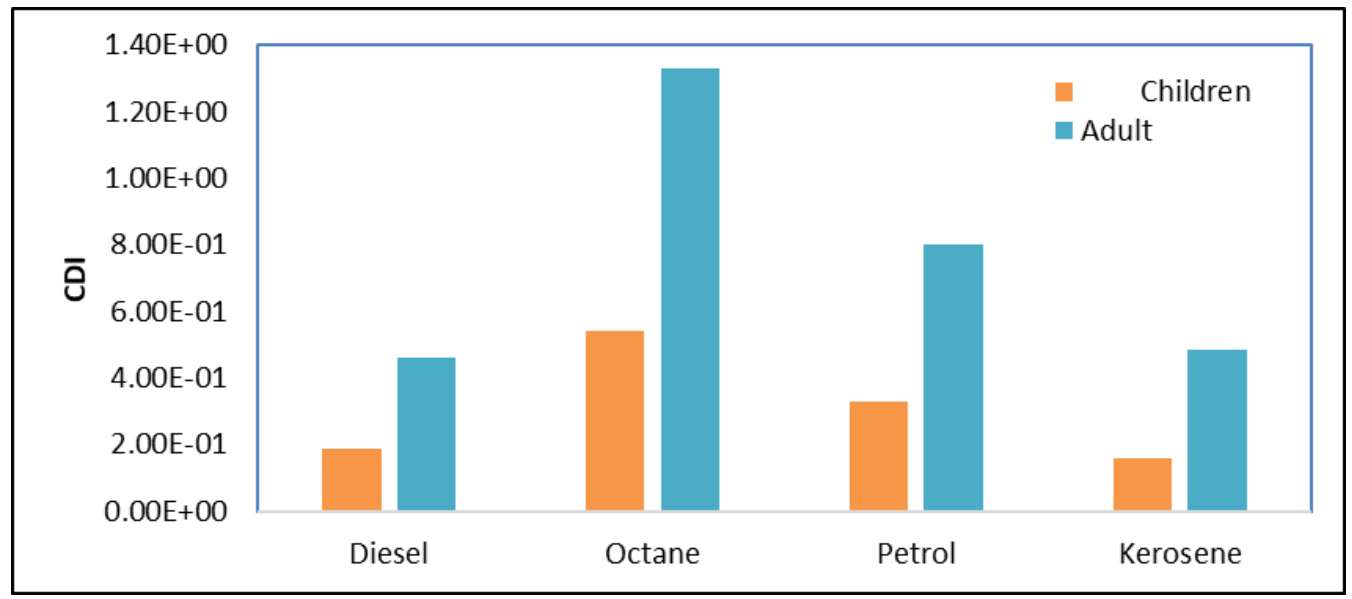

Figure 2: Comparison of chronic daily intake (CDI) between children and adults

From Figure 2, it is evident that adults were found to have higher CDI level as compared to children. It predicts that adults will have comparatively higher cancer risk (CR) values than children. Total CDI for children was $1.22 \mathrm{mgKg}^{-1} \mathrm{day}^{-1}$ and that for adults it was $3.08 \mathrm{mgKg}^{-1} \mathrm{day}^{-1}$. Adults were found to have 2.52 times higher chronic daily intake than children (Table 3 ).

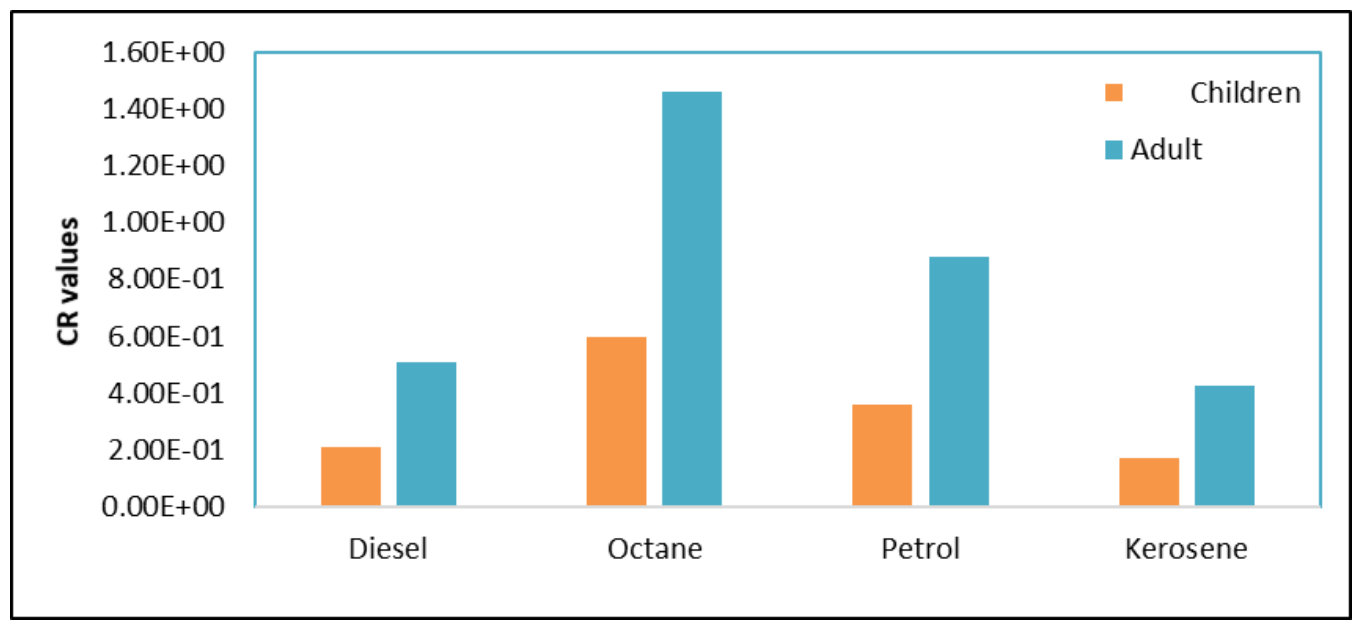

Figure 3: Comparison of cancer risk (CR) between children and adults

As recommended by U.S.EPA protocol, acceptable risk levels for carcinogens should be larger than $10^{-6}$ (EPA 2000). Carcinogenic risk for adults and children due to BC exposure have been found to be much higher than the permissible limit $10^{-6}$ as shown in Table 3. This indicates that black carbon exposure may bring about considerable carcinogenic health hazard. The order of CR caused by these fuels was $\mathrm{CR}($ Octane $)>\mathrm{CR}(\mathrm{Petrol})>$ 
$\mathrm{CR}($ Diesel $)>\mathrm{CR}($ Kerosene $)$. The total carcinogenic risk caused to exposed population was children(1.34) and adult (3.27). Adults were found to have approximately 2.4 times higher cancer risk than children (Figure 3).

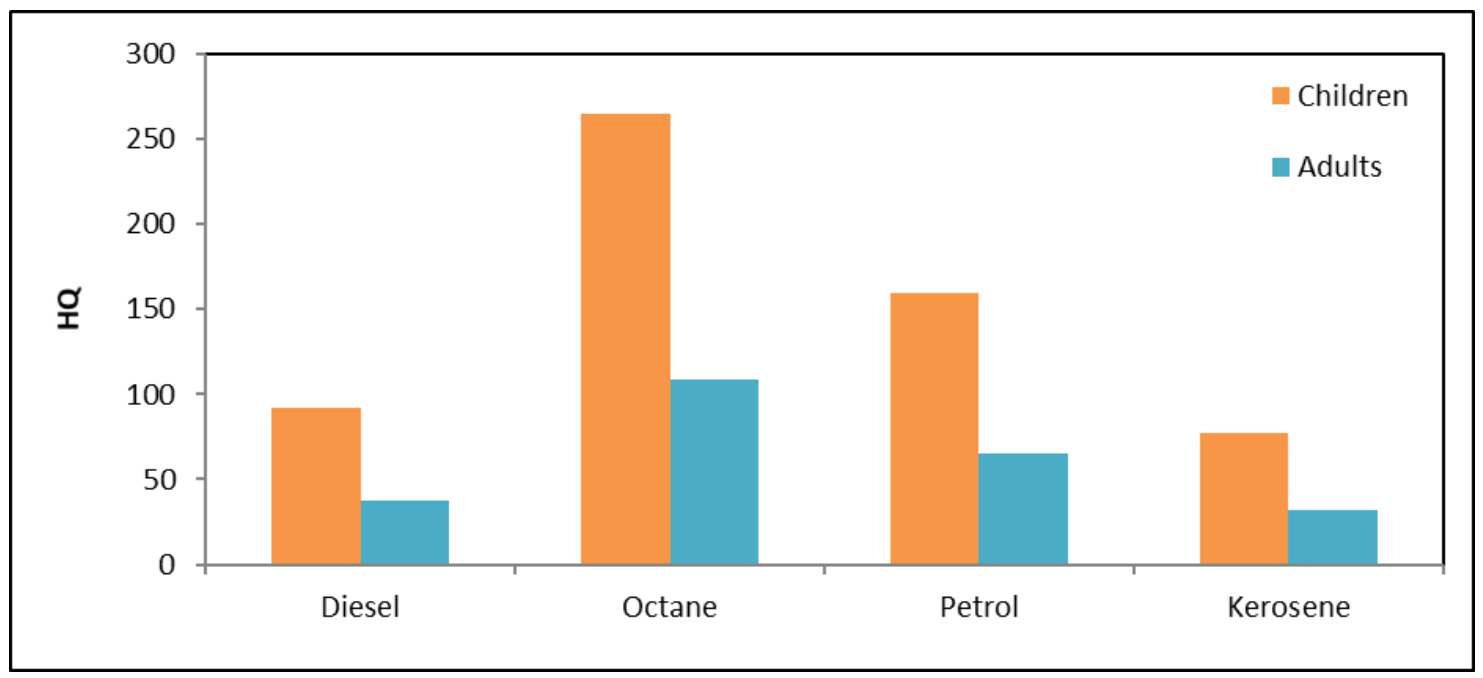

Figure 4: Comparison of non-cancer risk (HQ) between children and adults

The HQ value greater than unity suggests that the exposed pollution likely to have harmful non-cancer effect, according to USEPA protocol (EPA, 2000). In our study, HQ values obtained from experimental data were much larger than 1 (unity). Total non-carcinogenic risk in terms of hazard quotient (HQ) caused to exposed population was adult (243.32) and children (594.32) (Table 2).

These results indicate that exposure to $\mathrm{BC}$ is quite responsible for producing adverse non-cancer effects. Moreover, (Figure 2) displays that, Children have 2.4 times higher HQ values as compared to adults; which suggests that children are more prone to suffer non-cancer diseases than adults.

\section{CONCLUSIONS}

Our findings indicate that the black carbon (BC) emission from various vehicles running on Dhaka city street create environmental and health effect. The average concentrations of black carbon (BC) and brown carbon $(\mathrm{BrC})$ in the combustion smoke of fuel samples were found to be 7.38 and $11.46 \mathrm{mgm}^{-3}$, respectively. Brown carbon concentrations were higher than black carbon concentrations for all the four fuel samples. Our results show that, carcinogenic risks of adults and children due to $\mathrm{BC}$ exposure are higher than the acceptable risk level recommended by US EPA protocol. Total cancer risk was found to be 3.27 for adults and 1.34 for children. Also, hazard quotient (HQ) which defines the non-carcinogenic risk was much larger than 'one' indicating that the exposed population is likely to have adverse non-cancer effects. Total non-cancer risk was found to be 243.32 and 594.32 for adults and children, respectively which implies that children are more prone to suffer from non-cancer diseases than adults which cross it permissible level 1 (unity) set by US EPA in 2009. In view of the magnitude of our reported effects, reduction of BC emission could lead to substantial health benefits.

\section{REFERENCES}

Adler, G., Flores, J.M., Riziq, A.A., Borrmann, S, Rudich, Y., 2011. Chemical, physical and optical evolution of biomass burning aerosols: a case study. Atmos. Chem. Phys. 1491-1503.

Bond,T.C., 2001. Spectral dependence of visible light absorption by carbonaceous particles emitted from coal combustion, Geophys. Res. Lett. 28, 4075-4078.

Bond,T.C., Streets, D.G., Yarber,K.F., Nelson, S.M., Woo,J.H., 2004. A technology based global inventory of black and organic carbon emissions from combustion. J. Geophys.Res.Atmos. 1-43.

BRTA(Bangladesh Road Transport Authority), 2020. Air pollution in Bangladesh, BRTA associated with greater Dhaka metropolitan Area Integrated Transport Study, working paper no. 23. 
Cheng, Y.H., Yang, L.S., 2015. Correcting Aethalometer black carbon data for measurement artifacts by using inter-comparison methodology used on two different light attenuation increasing rates. Atmos.Meas.Tech. 2851-2879.

Coz, E., Guldris, J.P., Calvo, A.L., Alves, C., Tarelho, L.A.C., Ramos, G., 2014. A study on the structural properties of aerosols from biomass combustion for domestic heating. Italian Association of Chemical Engineering; 811-816.

Deng, W.J., Zheng, H.L., Tsui, A.K.Y., 2016. Measurement and health risk assessment of PM2.5, flame retardants, carbonyls and black carbon in indoor and outdoor air in kindergartens in Hong Kong. Environ.Int. 96, 65-74.

Feng, Z.B.; Cao, S.J.(2019). A Newly Developed Electrostatic Enhanced Pleated Air Filters towards the Improvement of Energy and Filtration Efficiency.Sustainable Cities and Society, 546-569.

Lin,W., Dai,J., Liu,R., Zhai,Y., Yue, D., Hu,Q., 2019. Integrated assessment of health risk and climate effects of black carbon in the Pearl River Delta region, China. Environ.Res.2019, doi: https://doi.org/10.1016/j.envres.2019.06.003.

Navid Ghanavati, Ahad Nazarpour, Michael J. Watts. (2019). Status, source, ecological and health risk assessment of toxic metals and polycyclic aromatic hydrocarbons (PAHs) in street dust of Abadan, Iran. CATENA, 177(7): 246-259.

Olson, M.R., Garcia, M.V., Robinson, M. A., Van Rooy, P., Dietenberger,M. A., Bergin, M., Schauer,J.J., 2015. Investigation of black and brown carbon multiple-wavelength-dependent light absorption from biomass and fossil fuel combustion source emissions.Geophys. Res.Atmos. 120, 66826697,doi:10.1002/2014JD022970.

Patterson, E. M. and McMahon, C. K., 1984. Absorption characteristics of forest fire particulate matter. Atmos. Environ. 18, 2541-2551.

Salam, A., Ullah, M.B., Islam, M.S., Salam, M.A., Ullah, S.M., 2013. Carbonaceous species in total suspended particulate matters at different urban and suburban locations in the greater Dhaka region, Bangladesh. Air Qual. Atmos.Health, 239-245.

Tracy,T.L., Kirchstetter,T.W., Malejan,C.J., Ward,C.E., 2014. Infiltration of black carbon particles from residential wood smoke into nearby homes. Open J. Air Pollut. 3,111-120.

U.S. Environmental Protection Agency (EPA): Risk Characterization Handbook. USEPA Office of Research and Development, Washington, DC, EPA-100-B-00-002, 2000.

U.S. Environmental Protection Agency (EPA): Risk Assessment Guidance for Superfund Volume I: Human Health Evaluation Manual (Part F, Supplemental Guidance for Inhalation Risk Assessment). USEPA Office of Research and Development, Washington, DC, EPA-540-R-070-002 0SWER 9285 7-82, 2009.

U.S. EPA. Human Health Risk Assessment. https://www.epa.gov/risk/human-health-risk-assessment. (accessed Nov 15,2019).

Vanloon, G.W. and Duffy, S.J., 2011. Environmental Chemistry- A Global Perspective, 3rd ed.; Oxford University Press: New York. pp 131-133.

(C) 2021 the Authors. Journal of Engineering Science published by Faculty of Civil Engineering, Khulna University of Engineering \& Technology. This is an open access article under the terms of the Creative Commons AttributionNonCommercial-NoDerivatives License, which permits use and distribution in any medium, provided the original work is properly cited, the use is non-commercial and no Modifications or adaptations are made. 